\title{
EL CONTROL DE LOS NIÑOS MORISCOS \\ EN ALICANTE TRAS EL DECRETO \\ DE EXPULSION DE 1609
}

\section{Mario MARTINEZ GOMIS}

Universidad de Alicante

1. - La cuestión de los «niños moriscos» valencianos relacionada con los hechos del extrañamiento de la población islámica en 1609 , carece hasta la fecha, de un trabajo que sitúe el asunto a la altura de las conclusiones a que se ha llegado en otros aspectos —demográficos, económicos, ideológicos, etc. - vinculados con la expulsión. Un sugerente artículo de Miquel Barceló (1) exponiendo la necesidad de revisar los coeficientes demográficos aplicados a la familia morisca y la mera transcripción de un manifiesto de los hijos de cristianos nuevos que quedaron en Onteniente en 1611 , realizada por Vicente Castañeda (2) son los únicos trabajos que abordan de un modo directo esta cuestión que ha sido, por otra parte, tratada incluso con

(1) M. BARCELO, "Els nins moriscos», Primer Congreso de Historia del País Valenciano, Valencia 1976, III, pp. 327-331.

(2) V. CASTAÑEDA, «Manifestación de los hijos de Moriscos que quedaron en la Villa de Onteniente al verificarse la expulsión de éstos del Reino de Valencia, 161 l », Boletín de la Real Academia de la Historia. tomo LXXXII, 1923, op. 421-427. 
mayor detalle en obras de carácter más general (3). El hecho indudable de la «escasa tracendencia estadística» (4) que ofrece en cifras absolutas el número de niños que quedaron en tierras valencianas a partir de 1610 (5) puede haber sido, - junto a la dificultad que presenta el recoger todo un disperso y heterogéneo material en los archivos locales que complete la documentación existente en la sección Estado de Simancas (6)-- una de las causas que han motivado el olvido de este aspecto en el que parece finalizar la presencia morisca en nuestro suelo.

No obstante estos inconvenientes, creemos que el problema de los niños moriscos no debe darse por concluido por el hecho de haber sido valorado preferentemente desde el punto de vista cuantitativo. Las implicaciones ideológicas que rodearon el tema, apuntadas por varios autores (7): las inquietudes políticas, incluso los intereses económicos que surgieron durante las discusiones que precedieron a la expulsión y que iban a decidir la suerte de los niños, son aspectos cuyo estudio puede ayudarnos a comprender mejor la sociedad que vivió aquellos momentos del éxodo forzoso y las circunstancias que lo propiciaron.

Por otra parte, y dado el carácter de la documentación, en especial el estudio de los registros de niños moriscos llevados a cabo por los comisarios que se ocuparon de su control, contrastado con otras informaciones de los archivos locales, resulta un excelente material para trabajar el tema. A través de este material se puede hacer posible la evaluación, en cifras relativas, de la importancia numérica de los niños que quedaron repartidos por muchas ciudades y lugares del Reino; determinar cuál era su procedencia, cómo se realizó su adscripción a los diferentes grupos sociales que se hicieron cargo de ellos, quiénes fueron éstos y qué facilidades o inconveniente, por último, pudieron ofrecerles de cara a su integración dentro de la sociedad cristiano-vieja. Cuestiones éstas que cerrarían de un modo más defini-

(3) Es siginificativo a! respecto la gran cantidad de información que of rece sobre el tema $P$. BORONAT Y BARRACHINA en su clásica obra Los moriscos españoles y su expulsión. Estudio histórico crítico, 2vol., Valencia 1901. También son abundantes las referencias al problema en $\mathrm{A}$. DOMINGUEZ ORTIZ Y $\mathrm{B}$. VINCENT, Historia de los moriscos. Vida y tragedia de una minoría, Madrid 1978; T. HALPERING DONGUI, Un conflicto nacional: moriscos y cristianos viejos en Valencia, Valencia, 1980; H. LAPEYRE, Geographie de l'Espagne morisque, París 1959 y J. REGLA CAMPISTOL, Estudios sobre los moriscos, Valencia $1974,3{ }^{2}{ }^{2}$ ede., por citar los trabajos más representativos.

(4) A. DOMINGUEZ ORTIZ Y B. VINCENT, Op. cit., pp. 185.

(5) Según H. LAPEYRE, Op. cit. pp 66, fueron 2.450 niños los presentados en uno de los últimos registros conocidos fechado a finales de 1611.

(6) Nos referimos a los registros de niños moriscos realizados en 1611 durante la campaña de control reaiizada por el comisario real D. García Bravo de Aciña que se encuentra en la Sección Estado del citado Archivo, !egajos 233, 241 y 243.

(7) Véase nota (4). 
tivo el caso y que podrían servir para clarificar los posibles residuos culturales o etnográficos moriscos que quedasen tras la expulsión.

El propósito del presente artículo, a partir del estudio de la documentación existente sobre el control de los niños moriscos en el Archivo Municipal de Alicante y en las iglesias de Santa María y San Nicolás de esta ciudad, es una primera toma de contacto con un tema sobre el cual trabajamos en la actualidad y sólo pretende - además de contribuir a rellenar una parcela de la historia local- el tratar de verificar alguna de las hipótesis aludidas o, cuando menos, el dejar planteadas una serie de preguntas que sólo podrán tener una respuesta más concluyente cuando hayamos elaborado los datos que poseemos de Simancas y de otras ciudades y poblaciones del Reino.

II.-

Dos son, a nuestro modo de ver, las principales cuestiones en que se centra, a nivel general, el tema de los niños morisces: por un lado las discusiones que a alto nivel tuvieron lugar desde los meses que precedieron a la expulsión hasta primeros de junio de 1610 tratando la suerte que debian seguir éstos; por otro lado, el carácter contradictorio unas veces, precipitado otras, de las decisiones en que concluyeron algunos puntos de la polémica. Decisiones que se tradujeron en órdenes y contraórdenes que, lejos de lograr una rápida y eficaz solución del problema, lo complicaron hasta el punto de dejar que fuesen al fin los hechos consumados quienes dictasen las resoluciones que habían de concluir con los inconvenientes que estaba causando la presencia anómala de los niños moriscos en el Reino de Valencia.

Para tratar de sintetizar estos puntos hemos partido de la rica aportación documental ofrecida por P. Boronat (8) con el fin de sentar mejor las bases que nos lleven a tratar la particularidad del caso de Alicante.

En efecto, entre el 27 de agosto de 1609 y el 15 de septiembre del mismo año, unos días antes de que fuese publicado el célebre bando que ordenaba la expulsión, los tres grandes problemas que planteaban los niños moriscos volvían a salir sobre el tapete de las consultas al Consejo de Estado y venían a mostrar su carácter abiertamente polémico. Estos tres problemas, como es sabido, se reducían a determinar las razones que justificasen la excepción de los menores al éxodo; explicar las condiciones que debían reunir los niños que fueran exceptuados y, por último, aclarar la situación en que habían de quedar bajo la tutela de los cristianos viejos para proceder a su integración religiosa y cultural.

El 27 de agosto, el Patriarca Ribera en carta a Felipe III (9) abogaba

(8) P. BORONAI, Op. (it

(9) Ibídem, Vol. II, Apéndice documental, pp. 522-524. 
por la necesidad de impedir la salida de los menores de once años, en virtud de que estaban bautizados y no se debía, por razón de la apostasía de sus padres, dejar que cayeran en los mismos errores. La elección de esta edad tope, como señaló M. Barceló, se fundaba también en motivaciones de tipo político, puesto que sé elegía a los menores de esta edad por considerarles que no estaban en condiciones de «ofrecer una resistencia armada al genocidio» (10). En el mismo documento, el Patriarca, además de dictar algunas normas para el cuidado de los lactantes, especificaba la situación en que debían de quedar los muchachos y muchachas que no salieran: bajo la tutela de

«...christianos viejos, officiales, o ciudadanos, con obligación de servirles hasta XXV o XXX años por sólo el comer y vestir» (11).

Del mismo parecer, a primeros de septiembre eran Fray Luis de Aliaga, confesor del monarca y el Consejo de Estado (12). Solo que Fray Luis de Aliaga era más explícito en cuanto hacia referencia a la cuestión de la tutela de los niños: los de once años abajo debían de quedar hasta que cumpliesen los veinticinco sirviendo a los cristianos viejos a cambio del sustento, pero siempre que se les dejase a:

«...officiales mecánicos que no sean armeros ni cosas de letras o a labradores para la cuitura del campo porque cuando sean grandes no aspiren a más de aquello que les hubieren enseñado».

Existía por lo tanto, una diferencia de matiz importante entre las ideas del arzobispo y las del confesor real: mientras el primero tendía a inclinarse porque ejercieran la protección de los niños las clases más pudientes, el segundo optaba por entregar la tutela al grupo menos peligroso, los campesinos, asegurando así a los niños una inhabilitación para cualquier tipo de resistencia - violenta o intelectual- contra la sociedad dominante, y condicionándolos a uno de los estratos sociales más bajos de la misma sin posibilidad de promoción.

Estas diferencias se hacían también patentes en el hecho de que el $\mathrm{Pa}$ triarca Ribera era partidario de dejar a los lactantes bajo el cuidado indirecto de los señores de lugares que, a su juicio, debían administrar una parte de los bienes incautados a los moriscos, para subvenir los gastos que causasen a las amas o tutores. Fray Luis de Aliaga, por el contrario, recelaba de la buena fe que pudieran tener los señores para con los hijos de vasallos y eludía, con su negativa al cumplimiento de la sugerencia del Patriarca, el delicado tema de administrar cualquier tipo de bienes. Es evidente que por estas fechas, el siempre centradictorio arzobispo, se inclinaba por compensar a los barones en las probables pérdidas económicas que iba a depararles là expulsión.

\footnotetext{
(10) M. BARCELO, Op. cil., pp. 327.

(11) P. BORONAT, Op. cit., Vol. II, Ap. doc. pp. 523.

(12) Ibidem, Vol. II, Ap. doc., pp. 524-526.
} 
El monarca, por su parte, oídas estas consuitas era del parecer de seguir las matizaciones hechas conjuntamente por su confesor y el Consejo y así se aprestaba a comunicarlo, a primeros de septiembre, tanto al Patriarca Ribera como al Marqués de Carecena y a Don Agustín Mexia. Estos dos personajes - futuros brazos ejecutores del éxodo- habían sido partidarios totalmente opuestos a la permanencia de los niños en el Reino tras la expulsión de sus padres (13). Su postura, idéntica a la sustentada por otros sectores de opinión valencianos -el P. Bleda o el agustino F.P. Arias, por ejemplo- partidarios de la expulsión total, estaba, sin embargo, lejos de deberse a razones de intolerancia religiosa. Obedecía más a cuestiones estratégicas y tácticas tendentes a hacer más eficaz la salida de los moriscos y así lo habrían de manifestar al Consejo de Estado, sin gran éxito:

\begin{abstract}
«...ha de ser grande el sentimiento de los moriscos de que se les quiten sus hijos y podría causar esto algún movimiento y dificultar la expulsión, se ha de ver si en tal caso se deve preferir el bien universal de la expulsión al particular de los niños» (14).
\end{abstract}

No faltaban, por supuesto, las ideas conciliadoras que, defendidas por una Junta de Teólogos en la que estaban presentes ios padres Salón y Sotelo, y Juan Pascual (15), se inclinaban por la posibilidad de dejar marchar a los mayores de 4 ó 5 años. El argumento esgrimido en defensa de esta opción se debía a la consideración de que cuantos superaban esta edad se encontraban ya iniciados en la «secta de Mahoma» y, por lo tanto, iba a resultar muy difícil su asimilación, cosa que no ocurriría con los más pequeños, en el caso de que se encontrasen los medios económicos adecuados para su crianza. La Junta de Teólogos hacía especial hincapié en el hecho de que los niños que quedasen debían hacerlo en circunstancias que no viniesen a alterar el orden público. Especificaban también que si el Estado encontraba medios adecuados para la crianza de los menores de 4 años no debía dudar, incluso, en degollar a los padres que se negasen a dejarlos en suelo valenciano, siempre en razón de salvarles de la apostasía (16).

La seguridad en la asimilación de los menores de 4 años y el evitar el grave problema que pocría plantear el número excesivo de niños en el Reino, serian las razones que indujeron al Patriarca a cambiar de opinión en lo que respecta al tema de las edades (17) viniendo a optar hacia el 14 de septiembre, por lo sugerido por los teólogos (18).

(13) Ibidem, Vol. II, Ap. doc., p. 525.

(14) Ubídem, Vol. Il. Ap. doc., p. 548.

(15) Ibidem, Vol. II. Ap. doc., pp. 529-531.

(16) Ibidem. Vol. II. Ap. doc., p. 530.

(17) Para comprender mejor el cambio de opinión experimentado por el P. Ribera en cstas fechas véase M. BARCELO, Op. cit, pp. 327-328.

(18) P. BORONAT, Op. cit., Vol. II. Ap. doc., p. 536. 
No obstante lo próximo al bando de 22 de septiembre que estaban estas deliberaciones, la decisión final que debía regir para la expulsión se vio sustancialmente matizada en el célebre documento. En efecto, el artículo $9 .^{\circ}$ del bando explicitaba que podrian quedar los menores de 4 años que contasen con permiso paterno. Una mayor laxitud, pues, acompañaba esta decisión al eliminar toda actitud coactiva. Creemos que las opiniones aquí del Marqués de Caracena y de D. Agustín Mexia, encaminadas a evitar cualquier aitercado durante la marcha hacia la costa y los embarques, hubieron de tener su peso a la hora de suavizar la medida.

Es, sin embargo, el resto del articulado que presentaba las excepciones al éxodo, el que, sobre la práctica, lejos de aclarar de un modo concluyente el asunto, venía a complicarlo por su afán de contentar casi todos los intereses que podían salir perjudicados con el extrañamiento. El artículo 5, por ejemplo, destinado a paliar los males económicos que derivarían del abandono de los campos, permitía quedar el $6 \%$ de las casas con todos los nî̃íos $\mathrm{y}$ adolescentes que no hubieran contraido matrimonio, mientras que los números 10,11 y 12 consentían el permanecer a los hijos de matrimonios mixtos menores de seis años y a los adultos que hubiesen observacio determinadas pruebas de asimilación. Todo ello no hacía sino propiciar que, al amparo de cualquiera de estos enunciados, pudiese quedar un número indeterminado de niños de todas las edades. Esta indudable contradicción sólo podía tener un atenuante, y era el pensamiento de que iban a ser muy pocos los moriscos que deseasen aceprarlo, al tiempo que se pensaba que el control sobre los mismos iba a poder ser, por tanto, más er̂icaz de cara a su integración. No se contaba, por supuesto, con la respuesta de algunos cristianos viejos a la expulisión ni con los perıosos incidentes que iban a tener lugar en la Muela de Cortes y en el Valle de Laguar.

Artes de pasar a estos acontecimientos conviene plantearse una pregunta, y es si el conjunto de las deliberaciones de los teólogos y del Consejo de Estado había trascendido al bajo clero y éste había, en alguna medida, hecho partícipe a la comunidad de cristianos viejos de las diversas posturas en torno al problema de los niños y las ducas existentes al respecto. Es decir: si adernás de las excusas legales que se contenían en el bando para retener a cualquier niño morisco, estaban o no difundidos los pretextos morales para retenerlos y la justificación de su explotación económica, también debatida en las altas esferas, aunque no reflejadas en el decreto. Es muy probable que ìa respuesia en ambos casos sea afirmativa. All menos en cuanto conicierne a las razones morales sabemos que, antes de las revueltas de La Muela y Laguar, ante la negativa a abandonar los moriscos a sus hijos menores «advirtiendo esto la piedad de los valencianos se determinaron a hurtar cuantos podían» (19). En lo que hace referencia a las ventajas

(19) T. HALPERING DONGUi, Op. cit., p. 242. 
que se desprenderían del tutelaje - la adquisición de mano de obra gratuita para el trabajo campesino, artesanal o doméstico- el precedente de lo ocurrido en ia sublevación de Granada en el último tercio del siglo XVI (20) donde, tras los hechos armados, los niños moriscos quedaron encornendados a los cristianos viejos de la misma manera que había pretendido el $\mathrm{Pa}$ triarca, era un hecho no tan lejano como para no estar presentes en la menre de los interesados.

Sea como fuere el caso es que antes del 10 de octubre, realizándose ya la expulsión; el T̃ribunai del Santo Oficio hacía patente sus dudas acerca de cómo debían de aplicarse las excepciones a determinados casos concretos que planteaban algunos moriscos (21). El contenido, por otra parte, de los cuatro primeros artículos del bando de expulsión. imponiendo penas de muerte a los moriscos que pusiesen algún otstáculo a su extrañamiento, suponía dejarlos a merced de los cristianos viejos que podían, valiéndose de taies pretextos, el justificar incluso las penas que caerían sobre ellos si a su vez ponían impedimentos a su salida. Todos estos faciores, como es sabido, propiciaron lia retención forzosa por parte de muchos señores de sus vasallos moros, acentiaron, incluso, los actos de bandidaje en pos deí botín que pocía obtenerse de los indễensos expulsos (22) - y botín eran los riños-y justificaron los raptos de menores motivados por el excesivo celo religioso cie los cristianos (23).

Estas complicaciones, no obstante, en relación al tema concreto que estudiamos, no serían probablemente más que hechos aislados y la importancia de los mismos hemos de valorarla en relación a que sentaban un precedente sobre la fragilidad de la normativa reguladora del exodo y sobre la imposibiiidad, por parte del Estado, de proceder a un control más riguroso de su aplicación. Tal como señaló H. Lapeyre, la presencia en el Reino de moriscos que se habían acogido a las excepciones fue escasa (24), y a la luz de los datos numéricos realizados por el comisario de embarque don Cristóbal Sedeño - recientemente estudiados por E. Berenguer Cebriá (25) - el total de niños retenidos antes de diciembre de 1609 no fue muy a.preciable, ya que la cifra de menores embarcados sólo descendió de modo notable a partir de la represión de Laguar y, concretamente, en el puerto de

(20) R. BENITEZ SANCHEZ-BI_ANCO, «Guerra y sociedad: Málaga y los niños moriscos cautivos, 1569 ", Estudis, n. ${ }^{\circ}$ 3, Valencia 1974, pp. 31-54, y A. DOMINGUEZ ORTIZ Y B. VINCENT, Op. cit., p. 251.

(21) P. BORONAT, Op. cit., Vol. II. Ap. doc., pp. 555-557.

(22) Ibídem, Op. cit. Vol. II. p. 218.

(23) A. DOMINGUEZ ORTIZ Y B. VINCENT, Op. cit., p. 185.

(24) H. LAPEYRE, Op. cit., p. 63.

(25) F. LDINA MARTORELL y E. BERENGUFR CEBR IA, La expuisión de los moriscos de Valeicia : Cataluña según el comisario de embarque Don Cristóbal Sedeño, Bellaterra, 1980 , p. 41 . 
Denia donde fueron embarcados gran parte de los rebeldes de la montaña alicantina.

Es por tanto a partir de las revueltas cuando se agrava el probiema de los niños. Buena prueba de ello îue el informe que ei Marqués de Caracena mandó al rey días después de la rendición de los de Laguar, en eỉ que señalaba que:

«...avia desorden en que ios soldados assi de los tercios como de la milicia tenian por esciavos a los que avian tomado assi hombres de los revelados como mugeres y niños y los vendian, tratavan algunos de granjeria y querian heriarlos y embiarlos a vender a Castilla» (26).

Alarmaban ya estas acciones a las autoridades, entre otras razones:

«...porque a bueltas de los que se havian cogido en la montaña usaban del mismo rigor con los que no han sido reveiados lo qual no se podia verificar» (27).

La confusión, pues, se había hecho evidente y fue entonces cuando el Virrey decidio poner remedio a las irregularidades ordenando suspender la compra y venta de esclavos moriscos. Informado el monarca no tardó en aprobar la iniciativa del Marqués de Caracena, al tiernpo que, a instancias del Consejo de Estado, trataba de introducir otras medidas de control con la intención de clarificar la situación de los moriscos retenidos o apresados:

«...Seria bien ordenar al Miarques que embie relación particular del numero de estos moriscos y de las mujeres y niños que se tomaron antes de la rebelión y durante ella y después, y de los que han dexado los padres o parientes de su voluntad, declarando los lugares donde son y cuyos vasallos y las edades de todos y entre tanto de orden para que no se oculte ni traspongan» (28).

Pero el consejo del monarca tardaría todavía en llevarse a cabo. Antes de ello otra rueva orden, iejos de solucionar o regular cuanto concernía estrictamente a Ios niños, venđía a enmarañar más el asunto, a dificuítar nuevos controles y a ofrecer una nueva garantia de irnpunidad a quieries deseasen hacerse cargo de los muchachos. Nos referimos al decreto de 9 de enero de 1610 en el se optaba por revocar la excepción del $6 \%$ y en el que se indicaba a la vez que:

«...Tots los dits Moriscos, majors empero de dotze anys, que aixi per raho de la mercé de les dites sis cases, com per altra quealsevol causa se restaveri en lo present regne, exceptats tan solament los que ab llicencia de sa Excellencia del Archepiste de Valencia, Bisbes de Tortosa, Segorb; y Oriola hauran restat, sen vajen a embarcar» (29).

(26) P. BORONAT, Op. cil. Vol. II. Ap. doc., p. 561.

(27) Ibídem. Vol. II. Ap. doc., p. 561.

(28) Ibiciem. Vol. II. Ap. doc., p. 563.

(29) Ibidem. Vol. II. Ap. doc., p. 570. 
La orden, como puede observarse, venía a legalizar, de un modo explícito, la presencia de niños de hasta doce años, conectando así, en cierta medida, con las ideas sobre las edades que había propuesto el Patriarca en el informe de 27 de agosto del año anterior y contradiciendo lo ordenado en el bando de 22 de septiembre. La razón, sin duda, de ampliar la edad de los niños, estaría en función de que su número, debido a la eficacia de los embarques, había dejado de ser importante.

Por otra parte, un fragmento del mismo decreto de 9 de enero, nada claro por cierto, añadía dificultades al hecho de interpretar en qué condiciones habian de quedar esos menores de doce años. Si bien es verdad que el mes anterior se había prohibido que se les esclavizara, ahora, se indicaba de modo generai para todos los moriscos remisos al embarque que, si pasados tres días de la lectura del bando no se habían presentado a los comisarics, el rey daba licencia y permiso:

«...a qualsevol soldat, o altres qualsevol persones, ab que sien christians vells, que puixen capturar y pendrelos tals Moriscos... y servirse de aquelis com a esclaus legitimament presos en bona guerra» (30).

El propio monarca y el Real Fisco se reservaban incluso el tomar a moriscos -que no fuesen mujeres o niños-- para su servicio, previo pago de veinte ducados a su capturador, lo que sancionaba en cierta medida cualquier acción de este tipo llevada a cabo por gentes del pueblo y evidenciaba, como tantas otras veces durante los meses de la expulsión, la utilización que se podía hacer del morisco como bien económico a poco que trasgrediese cualquier ley.

La confusión radicaba aquí en el hecho de que la prohibición de reducir a esclavitud a las mujeres y niños moriscos parecía recaer sólo sobre el monarca y su Real Hacienda, en tanto semejaba conceder a sus súbditos la gracia de poder utilizarlos como esclavos en el caso de que no se presentasen a los comisarios. Nada claro estaba el asunto cuando el Maraués de Caracena, mediante un nuevo bando de 10 de febrero de 1610 , hubo cie prohibir tácitamente todo intento de esclavizar a las mujeres y niños moriscos que quedaban en el Reino, sin que se llegase por ello a una solución real del problema.

El tema de la esclavitud, surgía, pues, en el momer $\ldots$ se los embarques habían prácticamente finalizado, y cuando en rock había estado ausente de la preocupación de teólogos y juristas duranie agosto y diciembre de 1609 , los meses críticos de la expulsión.

No se trataba, por supuesto, de un tema nuevo. Muchos autores a últimos del siglo insistieron -como el agustino Fray P. Ariac- en la necesi-

(30) Ibídem. Vol. Il. Ap. doc., p. 570. 
dad y justicia de esclavizar a los hijos de moriscos (31). El propio Patriarca Ribera, en abril de 1609 , antes de uno de sus bruscos cambios de decisión, había afirmado lo mismo (32) para inclinarse más tarde por la idea del tutelaje a cambio del sustento hasta la edad de 25 ó 30 años, corno ya quedó dicho. Ahora, en 24 de marzo de 1610, según trasluce una consulta del Consejo de Estado (33) volvía a considerar la necesidad de que los niños de 12 años abajo quedasen como esclavos, aduciendo para ello que esta condición redundaría en su propio bien en tanto y cuanto los cristianos viejos cuidaran de ellos como de «hazienda suya perpetua». Su idea de compensar a la pequeña nobleza volvía de nuevo a surgir al hacer referencia en el mismo documento al estado en que debían de quedar las mujeres moriscas que no tuviesen maridos ni hijos, ya que «los cavalleros y ciudadanos ternian por mucha comodidad poderse servir dellas porque no hallan servicio» (34).

Las cosas, pues, estaban lejos de llegar a una solución concluyente durante los tres primeros meses de 1610 . Debido a esta razón, el Consejo de Estado y una Junta de Teólogos reunida en Lerma -integrada por los confesores de la familia real- comenzó a deliberar sobre el caso con miras a ponerle un definitivo punto final.

El monarca a primeros de abril proponía una solución a consulta que distaba mucho de ser la ideal a juzgar por los resultados que la propuesta iba a tener. Esta consistía en sacar a todos los niños moriscos menores de 7 años que se hallasen repartidos por el Reino de Valencia y llevarlos hasta Castilla, donde debían permanecer al cuidado de cristianos viejos. La operación, pos supuesto, tenía que llevarse a cabo con mucho tacto ya:

«...que las personas que los crian en aquel reyno los aman y estiman de manera que sentirian mucho se les quitasen, mayormente avieñdo gastado ya con ellos en vestirlos y darles otro pelo» (35).

Lo más sorprendente de este proyecto, elaborado con la idea de erradicar toda presencia morisca de la siempre peligrosa costa, era la nueva decisión de expulsar a los mayores de 7 años. La Junta de Teólogos, en 25 de abril, aprobaba ambas decisiones (36), pero un mes más tarde, el 31 de mayo, (37) ratificaba tan sólo la necesidad de expeler a los de 7 años arriba que no debían quedar ni como esclavos, por mucha recesidad de personal

\footnotetext{
(31) Ibídem. Vol. II. p. 91.

(32) Ibídem. Vol. II., pp. 170-171.

(33) Ibídem, Vol. II. Ap. doc., pp. 573-574.

(34) İbídem. Vol. II. Ap. doc., p. 574.

(35) Ibídem. Vol. II. Ap. doc., p. 575.

(36) Ibidem. Vol. II. Ap. doc., pp. 577-579.

(37) Ibídem. Vol. II. Ap. doc., p. 581.
} 
para el servicio doméstico que tuvieran los barones. Se silenciaba, en cambio, toda referencia al hecho del traslado de los menores a Castilla. Este proyecto, a juzgar por la documentación que poseemos en Alicante (38) no se llevó jamás a cabo, a pesar de que parecía estar muy maduro. Se había elaborado, por ejemplo, un registro de los niños menores de esta edad que quedaban en el Reino, un total de 1.832 a primeros de abril (39) pensando incluso, en quiénes debían, a juicio de los teólogos, encagarse de la operación de traslado - el doctor Ancon de la orden de Alcántara y el cura de Ornachos- (40), pero los inconvenientes burocráticos, y sobre todo económicos, debier on paralizar la idea. El problema radicaba en quién se iba a hacer cargo del sustento y cuidado de los casi dos millares de niños mientras se les buscaba el tutor adecuado en Castilla. Tampoco la idea de expulsar a los mayores de 7 años cuajó, puesto que el Marqués de Caracena, el 22 de mayo, - mientras continuaban las deliberaciones de los teólogos-, ordenaba publicar un bando en Valencia donde se decía que:

«...los muchachos moriscos de siete años arriba no pueden estar ni vivir en ningun lugar maritimo de este Reyno, sino tres leguas la tierra adentro» (41).

pero en el que no se indicaba nada sobre su expulsión.

El contenido de este bando, - sin que hayamos podido averiguar las causas que a alto nivel de Estado lo propiciaron- iba a sentar ya algunas de las bases concluyentes sobre la complicada legislación que había intentado regular el terna de los niños. Por un lado permitía la presencia definitiva en territorio valenciano de los menores de siete años; por otro, se preocupaba tan sólo ya de controlar y alejar de la zona costera a los comprendidos entre 7 y 12 años, población ésta poco alarmante puesto que hacia el mes de agosto solo sumaba un total de 470 niños (42).

La labor de la administración a lo largo de todo el verano de 1610 , se encaminó, en especial, a vigilar el cumplimiento riguroso de cuanto hacía referencia al retiro de la franja litoral de los mayores de 7 años, sin que se lograsen resultados muy positivos. Ni las severas penas que se imponían a los poseedores de niños que no cumplieran esta orden (43), ni los registros llevados a cabo por el comisario D. Francisco de Vargas, lograron intimidar a los tutores haciendo que se desprendiesen de sus protegidos. Lo contradictorio de las ordenanzas, la escasa eficacia de su aplicación anterior, estaba logrando sus efectos entre los cristianos viejos.

(38) Archivo Municipal de Alicante (en adelante A.M.A.), Llibre de provisions reals de la ciutat de Alacant, 1609. Lib. 18., Arm. n. ${ }^{\circ} 1$, fols. 72-73.

(39) P. BORONAT, Op. cit., Vol. I1. Ap. doc., p. 575.

(40) Ibidem. Vol. Il. Ap. doc, , p. 578.

(41) A.M.A. Llibre de provisions reals..., fols. 72-73.

(42) H. LAPEYRE, Op. cit., p. 64.

(43) Véase nota (41). 
Hasta el 20 de febrero de 1611 no poseemos noticias bibliográficas ni documentales sobre el tema. Para esta fecha, una carta real que se traducía en decreto el 29 de agosto del mismo año (44) venía a tratar de poner punto final definitivo a la cuestión de los niños aceptando ya, como quedó dicho al principio, hechos consumados. En este documento la tolerancia se extendía hasta los niños de 14 años, sin que se hiciese ninguna referencia al apartamiento de la costa. La ampliación de la edad permisible - a dos años vista del decreto de expulsión - venía a legalizar las posturas que habían defendido durante 1610 el que restasen los niños de 12 años abajo. La ausencia de condiciones restrictivas, ahora, se debía sin duda a la dura campaña de represión del bandolerismo morisco en las montañas llevada a cabo por el comisario Don García Bravo de Acuña entre mayo y agosto de 1611 (45). Este personaje, encargado de supervisar la tarea del Marqués de Caracena de acabar con los insurrectos que quedaban de las dos revueltas, había devuelto la tranquilidad a Valencia contribuyendo así a la creación de un ambiente más sereno para valorar en su justa medida el problema de los niños. Un total de 2.450 - según relación hecha por el mismo Don García Bravo de Acuña- dentro de un contexto de pacificación general, no podía ser motivo de alarma ya. Y ello se evidenciaba en los términos del decreto de 29 de agosto de 1611 que recogía las palabras del rey:

«...he resuelto, y os encargo y mando repartays essos niños y niñas entre los que los tienen, haziendo notar con mucho cuydado el número de los unos y los otros, los que'se reparten, y a quienes, y quantos, los nombres, señas, y edad de cada uno; y encargando a los dueños que miren por ellos, y su buena crianza, y sepan que han de dar cuenta dellos siempre que se les pidiere. $\mathrm{Y}$ avisareysme como sale esta traça: $\mathrm{Y}$ al Patriarca que fuesse a esa ciudad se encargara que se informe, y me avise cada año de las edades de esta gente, porque esto no se olvide...» (46).

A este aire de conclusión que cobraba el tema, se unían las últimas medidas de control formuladas para lograr la perfecta integración de los menores: que ningún cristiano viejo pudiera tener más de un niño a su cuidado para evitar todo tipo de solidaridad o nostalgia cultural; que cada tutor quedase con una copia del presente decreto y del registro del niño para poder ser contrastada con la relación que elaborasen los justicias y jurados de cara a futuras revisiones; que se les enseñase la doctrina cristiana y que no pudieran ser considerados como esclavos bajo ningún concepto. Sobre este último particular, sin embargo, no se especificaban condiciores aclaratorias de cara a conocer el tipo y tiempo de tutela al que debían quedar some-

(44) H. LAPEYRE, Op. cit., p. 66.

(45) Ibídem. pp. 66-67.

(46) Archivo Municipal de Elche (en adelante A.M.E.) Decreto de S.M. al Cap. Gral. de Valencia para que sean registrados los niños moriscos, a quiénes y cuántos: cuidando de que miresn por ellos y por su buena crianza, etc., Legajo $\mathrm{H} / 105 \mathrm{n} .^{0} \mathrm{1}^{\mathrm{a}}$. 
tidos. La última noticia al respecto, sin que sepamos si tuvo aplicación o no, era la expuesta por el Duque de Lerma al Patriarca Ribera en abril de 1610 (47), según la cual los niños debían ser enseñados y cuidados hasta los doce años, pasados los cuales debían servir a sus protectores por espacio de tantos años como hubiesen sido objeto de atenciones hasta alcanzar esta edad.

A pesar del silencio documental que se cierne sobre la regulación del tema de los niños a partir de este momento (no nos referimos, por supuesto, a las noticias aisladas o esporádicas que hacen alusión a ello) es posible que durante los años 1612 y 1613 , incluso algunos años después, siguieran realizándose registros por parte de las autoridades valencianas con el fin de vigilar el cumplimiento del decreto arriba comentado. Buena prueba de ello es el manifiesto que en la ciudad de Alicante se llevó a cabo el 9 de diciembre de 1614 (48), cuya relación se debía a órdenes concretas de Valencia y que hubo de tener su paralelo en otras ciudades del Reino. Elaborado por el comisario Fernando de Godoy, la relación se efectuó con la intención de controlar si el número de niños residentes en esta ciudad había aumentado con referencia a los recuentos anteriores, teniéndose noticia, como se tenía, de que muchos moriscos habían vuelto después de ser embarcados, a tierras alicantinas. Con este documento se cierra la información de tipo general que poseemos sobre el asunto, circunscribiéndose el resto de nuestras noticias a datos más o menos esporádicos sobre el área local que vamos a estudiar.

Es pues, dentro de este amplio contexío, que vamos a tratar de analizar el caso de los niños moriscos en Alicante, intentando completar alguno de los vanos que hayan podido quedar tanto en la cronología corno en la interpretación de los hechos hasta el momento expuestos.

III. - La presencia de los nińos en Alicante, ciudad de realengo que había vivido ajena a todo conflicto entre las dos típicas nacionalidades de la historia valenciana, se debe fundamentalmente a dos hechos: al haber sido la ciudad puerto de embarque por donde salieron comunidades moriscas del Valie del Vinalopó, Vega Baja del Segura y montañas de La Marina, y al haber participado voluntarios alicantinos en la campaña de Laguar, donde, al decir de las crónicas, tuvo lugar la mayor presa de niños y adultos, bajo la excusa del botín de guerra.

Del enorme trasiego de moriscos por la ciudad de Alicante durante los meses de la expulsión, da noticia conocida el cronista Bendicho

(47) P. BORONAT, Op. cit. Vol. II. Ap. doc., p. 576.

(48) A.M.A. Llibre de provisions reais..., fols. 90-101. Ver también Apéndice documental. 
(49)yH. Lapeyre liega a sumar entre septiembre y enero de 1610 una cifra de 30.204 embarcados por su puerto (50). Por otra parte, hacia inediados de noviembre de 1609 , el Concejo de Alicante organizó cuatro compañías de gente armada para socorrer en la guerra de Laguar; dos formadas por vecinos de la Ciudad y comandadas por los hermanos Antonio y Bernardo Mingot y por Juan Bauiista Canicia de Franqui; y otras dos reclutadas con gentes de San Juan y Muchamiel a cuya cabeza iba Esteban Briones (51). Estas tropas debieron, como había hecho el resto de los soldados del̀ tercio y las milicias activas, llevar hasta la Ciudad su botín de esclavos tal y como se desprende del memorial que el Obispo de Orihuela enviaba al rey el 10 de marzo de 1610 :

«...en Alicante y toda su hueria quedan muchos moriscos assi pequeños como grandes, assi hombres como mugeres, de $20,30,40$ y 50 años los quales les han trahydo como esclavos y los tienen por tales» (52).

Abandonados, pues, algunos por sus padres de forma voluntaria, con el fin de evitar los riesgos del viaje, vendidos otros para compensar sus pérdidas, o simplemente apresados durante los hechos de armas, Alicante comenzó a vivir los problemas de los niños moriscos según se evidencia de modo claro en los tres registros que se conservan en el Archivo Municipal de la Ciudad.

El primero de ellos, realizado entre los días quince y dieciséis de julio de 1610 (53), obedece a un propósico concreto ya conocido: el de controlar a la población morisca infantil con el fin de que no continuasen viviendo en Alicante los mayores de 7 años, que debían ser retirados tres leguas hacia el interior. Orden que, habiéridose dado el 22 de mayo anterior, no se habia cumplido. El documento en cuestión viene precedido de dos copias de carta del Marqués de Caracena en la que se nombra comisario para lievar a cabo esta misión a Don Francisco de Vargas, se le asignan dos colaboradores -el escribano real Pedro de Peralta y el alguacil Juan Gaytăn- y se especifican las instrucciones a seguir para ilevar a cabo el control: las penas en que incurrirán quienes no cumplan con el alejamiento de los niños, la colaboración que deben prestar las autoridades locales, etc. El hecho de que la fírma de una de estas copias se deba, por delegación del Virrey a Diego de Amburcea sitúa este documento dentro de la campaña generai àe control

(49) BENDICHO, Crónica... de Alicante. Edición y notas de F. Figueras Pacheco, Alicante 1960. p. 202.

(50) H. LAPEYRE, Op. cit., p. 62.

(51) G. ESCOLANO, Décadia primera de ha Historia de Valencia, Valencia, 1972. Libro X, Vol. VI columna 1943, y R. VIRARENS Y PASTOR, Crónica de Alicante, Alicante $19^{7}$, pp. 191 y siguientes.

(52) P. BORONAT, Op. cit. Vol. II. Ap. doc., p. 585.

(53) A.M.A., Llibre de provisions reais..., fols. 76-78. 
para todo el Reino organizada por este personaje durante el verano de 1610.

Se trata este primer registro de un documento realizado con precipitación a juzgar por la precariedad de los datos que aporta y en relación con los otros restantes. Simplemente se recoge en él el nombre del tutor, especificando tan sólo cuándo es eclesiástico, y. el nombre del niño o de la niña, seguido de la edad. El resto de los datos adicionales que aportamos sobre esta primera relación a la hora de su estuđđio, proceden de los que aparecen en los manifiestos posteriores, completados por otros que hemos encontrado en los libros parroquiales que hacen referencia a los bautismos «sub conditione» de algunos de estos niños (datos sobre la profesión o condición social del tutor y procedencia geográfica de los menores principalmente).

El segundo de los registros está fechado el 4 de octubre de 1611 (54), cuando el tema de retirar a los mayores de siete años tierra adentro, debido a la reiterada inobservancia que se hizo de ello, ha dejado de interesar a las autoridades. Se inscribe cronológicamente dentro de otra campaña de control importante, la realizada por Don García Bravo de Acuña, quien volvió a delegar en Don Francisco de Vargas las tareas de control para la zona de La Marina alicantina hasta Orihuela. Se trata de un manifiesto de niños más completo que el anterior, en tanto en cuanto aporta información sobre la profesión de muchos tutores, y además del nombre y edad de los menores, ofrece una breve descripción de los rasgos físicos más sobresalientes de cada uno de ellos con el propósito probabie de facilitar su identificación en futuras investigaciones. Los datos, en cambio, sobre la procedencia de los niños siguen siendo muy escasos y sólo se indican en pocas ocasiones. Es, por otra parte, el documento que presenta el mayor número de niños registrados, 123 frente a 94 que aparecen en el primero y 98 que se indican en el último (ver Cuadro n. ${ }^{\circ}$ ). Ello nos lleva a pensar que se produjo tal vez en condiciones mucho más relajadas que el anterior, y que, al no deberse a un cupo de edad restrictivo, el número de ocultaciones fue menor. La razón por la que el número de niños disminuyó en el tercer registro, podría deberse principalmente, al carácter meramente rutinario dei mismo, en unos tiempos en el que el problema estaba en vías de solución; pero también, en menor medida, a algunas desapariciones de niños, bien porque huyesen de sus tutores - lo que hemos podido constatar-, bien porque fuesen traspasados o vendidos a personas de otros lugares. No hay que descartar, por supuesto, los fallecimientos de algunos de estos morisquillos en el espacio comprendido entre 1609 y 1614 como evidenció para Novelda V. Sala Cañellas (55).

(54) A.M.A., Llibre de provisions reals..., fols. 83-88.

(55) V. SALA CAÑELLAS, Crónica de la Villa de Novelda. Aportación a su historia, Novelda, 1977, pp. 169-170. 
El tercer manifiesto fue realizado tres años más tarde, el 9 de ảiciembre de 1614 (56), por el comisario Don Fernando Godoy y de las circunstancias que lo motivaron hemos hablado en pảginas atrás. Sólo indicar que en él aparecen los datos más completos sobre la situación de los niños, uniéndose a los ya aportados en los anteriores el lugar de procedencia de un buen número de ellos.

El balance que ofrecen estos tres registros por sexos y edades es el que puede observarse en el Cuadro n. ${ }^{\circ} 1$.

\section{CUADRO N. ${ }^{\circ} 1$}

\begin{tabular}{|c|c|c|c|c|c|c|c|c|c|}
\hline \multirow[t]{2}{*}{$\begin{array}{c}\text { Edades por } \\
\text { años }\end{array}$} & \multicolumn{3}{|c|}{$\begin{array}{c}\text { Registro } n .^{\circ} 1 \\
16-7.1610 \\
\end{array}$} & \multicolumn{3}{|c|}{$\begin{array}{c}\text { Registro } n .^{\circ} 2 \\
4-10-1611 \\
\end{array}$} & \multicolumn{3}{|c|}{$\begin{array}{c}\text { Registro } n^{\circ}{ }^{\circ} \\
9.12-1614\end{array}$} \\
\hline & V & $\mathrm{H}$ & $\mathrm{T}$ & V & $H$ & $T$ & V & $\mathrm{H}$ & $\mathrm{T}$ \\
\hline Menos de 1 ......... & 1 & - & 1 & - & - & - & - & - & - \\
\hline 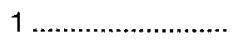 & 1 & 1 & 2 & - & - & - & - & - & - \\
\hline $2 \ldots \ldots \ldots \ldots \ldots \ldots \ldots$ & 1 & 1 & 2 & - & - & - & - & - & - \\
\hline З & 2 & 3 & 5 & - & - & - & - & - & - \\
\hline 4 & 5 & 6 & 11 & 5 & 2 & 7 & -- & - & - \\
\hline 5 & 4 & 7 & 11 & 6 & 4 & 10 & - & - & - \\
\hline 6 & 3 & 5 & 8 & 4 & 9 & 13 & - & - & - \\
\hline 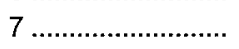 & 12 & 11 & 23 & 7 & 6 & 13 & 3 & 2 & 5 \\
\hline 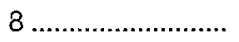 & $j$ & 14 & 15 & 9 & 10 & 19 & 3 & 4 & 7 \\
\hline 9 & 1 & 2 & 3 & 4 & 5 & 9 & 4 & 8 & 12 \\
\hline 10 & - & 3 & 3 & 7 & 6 & 13 & 5 & 5 & 10 \\
\hline $11 \ldots \ldots \ldots \ldots \ldots \ldots \ldots \ldots$ & - & 3 & 3 & 4 & 2 & 6 & 8 & 8 & 16 \\
\hline $12 \ldots \ldots \ldots \ldots \ldots$ & - & 1 & 1 & 4 & 4 & 8 & 5 & 4 & 9 \\
\hline $13 \ldots \ldots \ldots \ldots \ldots \ldots \ldots$ & - & - & - & 5 & 10 & 15 & 5 & 5 & 10 \\
\hline 14 & - & - & - & 4 & 5 & 9 & 3 & 3 & 6 \\
\hline $15 \ldots \ldots \ldots \ldots \ldots$ & - & - & - & - & - & - & 2 & 7 & 9 \\
\hline 16 & - & 1 & 1 & - & - & -- & 1 & 9 & 10 \\
\hline 17 & - & - & - & - & - & - & 2 & 2 & 4 \\
\hline $20 \ldots \ldots \ldots \ldots \ldots$ & - & 1 & 1 & - & - & - & - & - & - \\
\hline $\sin$ esp. & 4 & - & 4 & - & 1 & 1 & - & - & - \\
\hline TOTALES ............. & 35 & 59 & 94 & 59 & 64 & 123 & 41 & 57 & 98 \\
\hline
\end{tabular}

(56) Véase nota (48). 
Según este cuadro, en el registro de 1610, además de la destacada diferencia existente entre niños y niñas manifestados, (35 varones frente a 59 hembras) se aprecia también, un notable y lógico saldo a favor de los menores de 8 años - la edad permitida en ese momento, según la legislación, para quedar en la costa- ante los que sobrepasan dicha edad, concretamente 65 niños $(67,02 \%)$ por sólo 27 (el $28,72 \%$ ) de los considerados «ilegales».

Si tenemos en cuenta que la misión del registro en cuestión era la de contabilizar a la población infantil para verificar el cumplimiento de las órdenes dadas en mayo de ese mismo año, acerca del retiro hacia el interior de los mayores de 8 años, queda patente la inobservancia de la misma dos meses después de su publicación en Alicante. La existencia tan sólo de este documento podría habernos llevado a pensar que a partir de la fecha citada el mandato se había cumplido una vez controlados los niños que no podian permanecer en el litoral. Ahora bien, la presencia del Registro número 2, nos muestra que esto no sólo no sucedió así, sino que además, en el transcurso de un año, el número de niños que sobrepasaba la edad tope permitida para quedar en la ciudad se había elevad de 27 a 60 , con el agravante de que de esos 27,24 seguían permaneciendo en el segundo control con toda impunidad.

Es más que probable, pues, que las ocultaciones en el recuento de julio de 1610 fuesen muy abundantes; en especial de los varones que sobrepasaban la edad permitida, ya que sólo fueron presentados 2 en tanto y cuanto en octubre de 1611 aparecieron 28 . En cambio, en lo que hace referencia a las muchachas, el grado de ocultación debió de ser menor a juzgar por las cifras: si en julio de 1610 se contabilizaba un total de 25 muchachas mayores de 7 años, en octubre de 1611 la cantidad ascendía tan sólo a 32. La única explicación que encontramos a este hecho es la de que existiera una especie de discriminación en torno a la tolerancia de los niños basada en la distinción de sexos. Las niñas, por la extendida creencia de su mayor docilidad - y por tanto, de una mayor garantía de cara a su integracich-serian manifestadas con la esperanza de que el rigor de la orden no con ellas; en tanto y cuanto, los varones, que ya habian preocupres a las autoridades por lo temprano que podían estar capacitados para cia armada (57), serían ocultados en espera de tiempos

Esos tiempos, como es sabido, llegaban en octubre 10.2 , cuando la tolerancia se hacía extensiva hasta los 14 años.

Es necesario sin embargo, hacer una serie de matiaciones que no aparecen reflejadas en el cómputo expuesto de estos registos ca ci Cuadro n. ${ }^{\circ}$ 1; matizaciones que vienen a evidenciar lo complejo de no biema de los ni-

(57) P. BORONAT, Op. cit. Vol. UI. Ap. doc., p. 523. 
ños por un lado, y la debilidad, tantas veces aludida, de las autoridades para con el cumplimiento de las órdenes emanadas de Valencia.

En cuanto a las complicaciones del asunto, está el hecho de que a pesar del aumento experimentado en cifras globales por los niños entre uno y otro manifiesto (29 más a favor del segundo), se dio una importante desaparición de éstos entre septiembre de 1610 y octubre de 1611 . En efecto, 35 niños de los registrados en 1610 no aparecen en el documento posterior aunque ello no se aprecia numéricamente a causa de la aparición de otros menores que han venido a ocupar su lugar en ese espacio de tiempo.

¿Qué ha ocurrido con esos 35 niños desaparecidos? ¿De dónde proceden los nuevos? Resulta extremadamente complicado el llegar a una conclusión definitiva sobre este tema dada la carencia de documentación auxiliar con que contamos. Sin embargo existe un hecho destacable que no podemos pasar por alto, y es el que hace referencia a la edad de los niños desaparecidos. Entre ellos se encuentran, precisamente, los más pequeños (uno de 8 meses, uno de 16 meses, uno de 1 año, dos de 2 años, uno de 3 años, cuatro de 4 años,...); es decir, aquellos que se encuentran más expuestos a las enfermedades, dentro además, de las difíciles circunstancias por las que han atravesado. No podemos descartar por lo tanto la posibilidad del fallecimiento como una razón importante de su desaparición; máxime si tenemos encuenta dos cosas: una es que resulta harto difícil creer que hayan sido retirados tierra-adentro cuando no lo han sido aquellos sobre los que recaía la orden de un modo directo; otra es el hecho de que de los 35 desaparecidos sólo tres pertenezcan al grupo de los «ilegales», es decir de los de edad avanzada (58).

Apuntada, pues, la posibilidad de la muerte tenemos también otra razón que explique sus ausencias, sí verificada para algún caso: y es la ocultación motivada quizás por la dejadez de los tutores, como ocurre, por ejemplo, con dos menores, uno de 4 años y otro de 5 que fueron registrados en 1610 , se omitieron en el control de 1611 , y volvieron a ser presentados en 1614 (59).

Otras dos posibilidades existen todavía para justificar la desaparición: una la huída de los muchachos, cosa que hemos de descartar en razón de la escasa edad de los niños que faltan (sí se darán en cambio estos hechos en el registro de 1614 cuando los muchachos han alcanzado la edad idónea para valerse por sí solos); otra, por último, el traspaso o venta de algún niño a personas de fuera de la localidad (sabemos va de la tendencia a sacar niños

(58) Resulta imposible verificar las posibles defunciones de los niños dado que en los dos Archivos Parroquiales que hemos trabajado para este estudio - los correspondientes a las dos únicas iglesias del XVII alicantino- no existen para estas fechas libros de defunciones.

(59) A.M.A., Llibre de provisions reals..., Ver fol. 76 y fol. 95 para Miguel Morelo y fol. 78 y fol. 95 para Hieronimo Pasqual. 
a Castilla para venderlos) en especial a comerciantes italianos a través de la amplia colonia genovesa instalada en Alicante; colonia que, por otra parte, como veremos, acostumbrada a ejercer una no despreciable demanda de esclavos y se había visto excluida del reparto de los niños moriscos.

Queda todavía por dilucidar la aparición de los niños nuevos de este segundo registro, los que sustituyen a los ausentes y los que contribuyen al mayor saldo positivo del manifiesto: un total de 64 . De ellos 36 pertenecen a la edad «ilegal» y hay que pensar que fueron ocultos hasta pasar la prohibición que les impedía estar en la ciudad. El resto, 28, son menores de 9 años y la única justificación que encontramos a su omisión en el primer registro debemos atribuirla a idéntico motivo, o al hecho de que hubiesen llegado a Alicante con posterioridad a la fecha en que se realizó el primer control.

Nos inclinamos más por la primera hipótesis en virtud de la documentación existente sobre los niños en los libros de bautismo de las parroquias de San Nicolás y Santa María de Alicante (60). Es, también, en base a ella, y a cuanto llevamos dicho, que creemos que los 36 «ilegales» no venían de fuera, sino que estaban ocultos en la ciudad o algú lugar de su huerta aprovechándose de una vigilancia escasamente eficaz por parte de las autoridades. En efecto, en los bautismos «sub conditione», realizados en estas parroquias hacia noviembre de 1610 , aparecen bautizados, junto a muchos niños presentados en el primer registro, 26 de estos moriscos que hemos considerado «nuevos» en el segundo manifiesto. Pero lo que avala el hecho de las ocultaciones es que en San Nicolás de 74 niños bautizados de esta forma, 22 no aparecen en ninguno de los tres manifiestos, y lo mismo ocurre en Santa María, aunque en menor medida. En esta parroquia, de $26 \mathrm{ni}$ ños bautizados, 6 no aparecen tampoco en ninguno de los controles efectuados por la autoridad civil, lo que viene a demostrar la presencia continua de niños que escapan a estos controles, por lo menos hasta finales de 1611.

Otro aspecto que llama la atención del Cuadro n. ${ }^{\circ} \mathbf{1}$ es el que corresponde a las cifras del manifiesto de 1614. Como puede apreciarse el total de niños ha vuelto a disminuir (de 123 hemos pasado a 98) sin que sepamos las causas que han motivado de nuevo su desaparición. La omisión del registro, el traspaso o venta, y la huída, son las hipótesis que hemos de volver a barajar como razón de esta ausencia. Algunos, como adelantábamos ya en otro lugar, han escapado de sus tutores debido tal vez a los malos tratos: Miguel, un niño de 12 años natural de Laguar, que desde los 7 había estado al servicio de Juan de Avellán, un oficial del Santo Oficio; Luis Juan, de 17 años, nacido en el vall de Albaida y que desde los 14 estaba en casa del no-

(60) Archivo Parroquial de San Nicolás de Alicante (en adelante A.P.S.N.) Libro de bautismos 1609-1625; Archivo Parroquial de Santa María de Alicante (en adelante A.P.S.M.) Libro de bautismos 1606-1646. 
tario Francesc Juan; Antonio, de 9 años, de Gata, que había estado bajo la tutela de Simón Planelles (61). Tres casos concretos que no dicen mucho sobre el conjunto pero que avalan la probabilidad de estas acciones.

Tal vez más interesante que este aspecto, y más elocuente, es el vacío que presenta este manifiesto entre los 0 y los 7 años. Vacío que muestra a las claras el progresivo envejecimiento de estos elementos residuales de la nación morisca. Ello se debe a que, indudablemente, por estas fechas, el problema de los niños va remitiendo. Es posible que sigan existiendo niños incontrolados, pero en todo caso son niños que pertenecen a la generación de la expulsión y no a nacidos después de ella. Máxime si tenemos en cuenta que este registro, a pesar de que fue llevado a cabo a instancias del rumor existente sobre el regreso de moriscos que habían sido embarcados tiempo atrás, no presenta ninguna novedad relevante. Solo 7 niños «nuevos» aparecen en él en relación con el manifiesto anterior, y los 7 se encuentran por encima de los 8 años. El $92,8 \%$ de los niños presentados en este registro, por lo tanto, habían sido ya contabilizados en uno u otro de los manifiestos estudiados; concretamente $47(47,9 \%)$ se encontraban en Alicante desde julio de 1610 , y $44(44,8 \%)$ lo estaban desde octubre de 1611 . La población infantil - al menos la controlada por la autoridad civil- se estaba, pues, estabilizando.

Hemos esbozado en páginas anteriores algunas consideraciones acerca de la causa por la cual los niños moriscos vinieron a quedar en Alicante. Los argumentos entonces esgrimidos vamos a tratar de completarlos mediante el análisis de la condición social de los tutores que se hicieron cargo de ellos (Cuadro n. ${ }^{\circ}$ 2) y el estudio de los lugares de procedencia de los niños (Cuadro n. ${ }^{\circ}$ ). De estos datos queremos sacar, también, algunas conclusiones que nos lleven a determinar del modo más aproximado posible, cuál fue la condición bajo la que quedaron sometidos los niños y qué futuro pudo aguardarles dentro de la ciudad.

Existe en este reparto de los niños, al menos en lo que concierne at Registro n." 1, una curiosa coincidencia con los porcentajes elaborados por R. Benites para el estudio de los niños cautivos durante la (iuerra de Granada en 1569, que fucron llevados a Malaga (62). I a coincidencia, no es ajena a la premeditación, en tanto y cuanto su artículo ha servido de base al nuestro y, en virtud de ello, hemos repartido en los mismos grupos socioprofesionales las distintas actividades a que se dedicaron los tutores de los niños. Salvo matizaciones exclusivas del trabajo de R. Benites, cslats coincidencias que, a nuestro modo de ver, se deben a formas de coniportamiento denticas entre la sociedad malacitana y alicantina para dos hechos similares aunque distintas en el tiempo, son las siguientes: primero el hecho de

(61) A.M.A. Llibre de provisions reals..., Ver Registro n. ${ }^{\circ}$ 3, fols. 98, 91 y 94.

(62) R. BENITEZ SANCHEZ-BLANCO, Op. cit. 


\section{CUADRO N. ${ }^{\circ} 2$}

\begin{tabular}{|c|c|c|c|c|c|c|}
\hline Grupo Socio- & Regi & $n .1$ & Regi & $n 0^{\circ} 2$ & & $n .{ }^{\circ} 3$ \\
\hline & & Porc. & & & & \\
\hline $\begin{array}{l}\text { Nobleza ciudadana y } \\
\text { altos funcionarios ......... } \\
\text { Gente de Carrera .......... } \\
\text { Eclesiásticos ............... } \\
\text { Empleados públicos .... }\end{array}$ & $\begin{array}{r}20 \\
6 \\
12 \\
6 \\
\end{array}$ & $\begin{array}{r}21,2 \% \\
6,3 \% \\
12,7 \% \\
6,3 \% \\
\end{array}$ & $\begin{array}{r}51 \\
10 \\
14 \\
5 \\
\end{array}$ & $\begin{array}{r}41,4 \% \\
8,13 \% \\
11,3 \% \\
4,0 \% \\
\end{array}$ & $\begin{array}{r}41 \\
9 \\
11 \\
6 \\
\end{array}$ & $\begin{array}{r}41,8 \% \\
9,1 \% \\
11,2 \% \\
6,1 \% \\
\end{array}$ \\
\hline Totales parciales ......... & 44 & $\overline{46,8 \%}$ & 80 & $6 \overline{65,0 \%}$ & 67 & $\overline{68,3 \%}$ \\
\hline $\begin{array}{l}\text { Gentes oficios mecáni- } \\
\text { cos y viles .............. } \\
\text { Agricultura y Ganade- }\end{array}$ & 5 & $5,3 \%$ & 9 & $7,3 \%$ & 9 & $9,1 \%$ \\
\hline 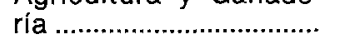 & 1 & $1,0 \%$ & 1 & $0,8 \%$ & - & - \\
\hline Totales parciales .......... & 6 & $6,3 \%$ & 10 & $8,1 \%$ & 9 & $9,1 \%$ \\
\hline $\begin{array}{l}\text { Viudas ........................... } \\
\text { Gentes sin especificar }\end{array}$ & 10 & $10,6 \%$ & 7 & $5,6 \%$ & 4 & $4,0 \%$ \\
\hline & 34 & $36,1 \%$ & 26 & $21,1 \%$ & 18 & $18,3 \%$ \\
\hline 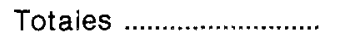 & 94 & & 123 & & 98 & \\
\hline
\end{tabular}

que sean precisamente los grupos privilegiados (nobleza ciudadana, eclesiásticos, gente de carrera y empleados públicos) los que detectan el $46 \% 8 \%$ de los niños registrados en Alicante, mient ras que en Málaga alcanzan el $42 \% 9 \%$ de un total de 170 registrados en esta ciudad; segundo el que el número de agricultores que consiguen la tutela de niños sea mínimo en ambas ciudades, 1 '0\% en Alicante, 2’3\% en Máaga; y tercero que el número de tutores que no especifican proiesión se aprovima también bastante, aunque este daro sólo venga a revelar la imperfección de los registros: $36^{\prime} 1 \%$ en Alicante y $28{ }^{\prime} 2 \%$ en Málaga. L.a diferencia más notable estriba entre los 4 utores oficios mecánicos y viles; el 5'3\% en Alicante y el 26'4 \% en Málaga. Otra muestra diferenciadora es el grupo de «viudas» que aparece en Alicante y que R. Benítez no incluyó, en toda lógica, dent ro de la división socioprolesional. Nosotros lo hemos hecho simplemente porque ningún dato adicional nos proporcionaba la categoría social de las mismas, y porque su número, dentro del contexto, tenía cierta importancia y era preferible el evidenciarlo a incluirlo en el anonimato de los «sin especificar».

Sobre el elevado porcentaje de tutores pertenecientes al grupo de la oligarquia urbana, hemos de pensar que su prestigio social y su poder económico serian unas de las razones determinantes a la hora de hacerse cargo de los niños; en especial de aquellos que quedasen con el consentimiento paterno, bien eedidos, ante la perspectiva de que podia aguardarles un estable bienestar bajo su tutela, bien mediante alguna especie de intercambio que compensase a los padres de su pérdida. Creemos, sin embargo, que las razones más poderosas para justificar el altomúmero de niños al cuidado 
de esı grupo se debería a la participación del mismo en la campaña de laguar. En efecto, como señala Escolano, la milicia activa alicant ina que marchó hacia las montañas estuvo también integrada principalnente por "caballeros y personas de lustre» (63); gentes que verían on el sofoco de la revuelta morisca no solo la oportunidad de rendir un servicio al Rey, como era su misión, sino también la oportunidad de adquirir prestigio y alguna compensacin económica: El botín de guerra del que formaban parte los ninos. El hecho de que los 71 niños cliya procedencia nos es conocida (ver cuadro $n^{\circ}$ 3) 59 fuesen originarios de la zona involucrada en los conflictos de Laguar - el foco de rebelión más próximo a Alicance- justifica nuestra apreciación. También a favor de ella aparece otro dato como es la coincidencia, al igual que habia ocurrido años antes en Málaga de que fuesen aqui tambien precisamente los caballeros, militares y clérigos, quienes obtuviesen en relación con el resto de los otros miembros de este grupo y de los restantes la mejor parte en botín. Así tenemos, en cilras globales, que en el primero de los registros, de las doce personas que present an más de un niño, sean precisamente cinco caballeros, un canónigo, un alguacil y un ciudadano (con dos menores cada uno a su cargo, a excepción de un caballero que manifiesta cuatro). El resto, los otros cuatro tutores alortunados en el reparto no especifican profesión. Vemos, asimismo, que entre los caballeros se encuentran precisamente los capitanes de la milicia Juan Baut ista Canicia, Esteban Briones y Bernardo Mingot, protagonistas principales en la misión de auxiliar a los tercios. En resumen podemos decir que en el manî̈iesto de 1610, ocho personas del grupo de los privilegiados detentan 18 niños (el 19'1\% de los manifestados). Este porcentaje se cleva en el control de 1611 en donde veinte personas de esta categoría social tienen al cuidado 40 niños (el $32,5 \%$ del total) mientras que en 1614 , catoree de los manifestantes de este grupo siguen presentando a 28 menores (el $28,5 \%$ ). Ninguna persona, por el contrario, de los otros sectores socioprofesionales poseen más de un niño a su cargo. Sólo lás cuatro personas aludidas en el primer manifiesto que no hacen relerencia a su estado, cuatro más en el segundo, y dos en el tercero y último poseen cada una dos niños.

Es interesante resaltar, sobre este particular, que la presencia de los menores en estas farnilias de más prestigio de la ciudad, unido al hecho de lo cambiante de las ordenanzas, sería un obstáculo no desdeñable para los oficiales del rey de cara a su cumplimiento, al tiempo que supondría una coartada ideal para que las personas de categoría social inferior las contraviniesen. Nos referimos por citar dos casos concretos al h echo de que no fuesen retirados los niños de la costa y a otro mandato del decretode29-81611 en el que se ordenaba que ningún cristiano viejo pudiese tener a su cuidado más de un niño, y que, como ha quedado visto, tampoco se cumplió ¿Influyó también en esta falta de control por parte de las autoridades la

(63) G. ESCOLANO, Op. cit. colurna 1974. 


\section{CUADRO N. ${ }^{\circ} 3$}

Poblaciones involucradas en la guerra de Laguar

\section{N. ${ }^{\circ}$ de niños}

\begin{tabular}{|c|c|}
\hline $\begin{array}{l}\text { Alcalá } \\
\text { Alcalalí } \\
\text { Benicasim }\left(^{*}\right) \\
\text { Benimasot } \\
\text { Benisembla } \\
\text { Callosa de Ensarriá } \\
\text { Cocentaina } \\
\text { Finestrat } \\
\text { Guadalest } \\
\text { Laguar } \\
\text { Mosquera } \\
\text { Relleu } \\
\text { Tárbena } \\
\text { Terrateig } \\
\text { Val de Albaida } \\
\text { Val de Seta } \\
\text { Xaló }\end{array}$ & $\begin{array}{r}1 \\
1 \\
1 \\
1 \\
1 \\
1 \\
1 \\
13 \\
6 \\
22 \\
2 \\
4 \\
1 \\
1 \\
1 \\
1 \\
1\end{array}$ \\
\hline
\end{tabular}

Poblaciones involucradas en la guerra de Cortes

\section{Cortes}

Val de Ayora

Zarra

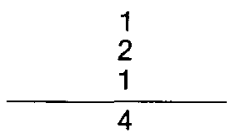

\section{Poblaciones ajenas a las revueltas}

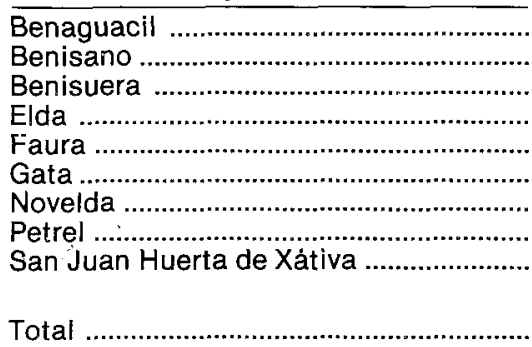

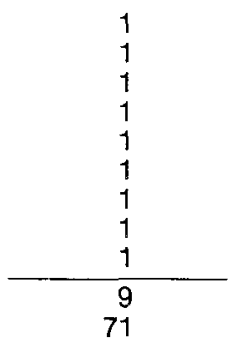

(*) Benicasim, despoblado de Guadalest (ver H. Lapeyre, Geographie de... pág. 45). 
idea de compensar mediante la entrega de niños las pérdidas económicas que suponía para algún grupo social la expulsión? (64). El clero, algunas gentes de carrera, las viudas y caballeros, fueron en Alicante y Elche los grupos que al decir de J. Regla «vivían del cupón» (65), de los intereses de los préstamos por el sistema de los censales, uno de los sectores más afectados, como sabemos, por el extrañamiento de los moriscos. Resulta aventurado el hacer una afirmación de este tipo y por ellos queremos tan solo dejar planteada la pregunta junto a una cuestión que parece avalarla, y es la de los consejos del P. Aliaga referidos al porvenir de los niños. Consejos o sugerencias que cayeron en saco roto tras contar con la aprobación real: el que los menores quedasen preferentemente en manos de agricultores y nunca entre gentes de armas y letras. El mínimo porcentaje de niños que quedaron en Alicante bajo la tutela de campesinos es altamente revelador: $1,0 \%, 0,8 \%$ y $0,0 \%$ respectivamente en cada uno de los tres registros. Y no tiene muchos visos de verosimilitud la posibilidad de que entre los que no especifican profesión se encontrasen los agricultores, ya que, como vemos, estos porcentajes que no indican el grupo socioprofesional al que pertenecen disminuyen progresivamente entre el primer y último registro, sin que se observe, por el contrario, ningún tipo de aumento en los apartados que hacen referencia a la agricultura. Las ideas del Patriarca Ribera acerca de satisfacer la demanda de puestos para el servicio doméstico de las clases más acomodadas, parece haberse cumplido a satisfacción en nuestra ciudad.

Resulta más extraño, dentro de esta misma cuestión, el explicar la escasa inmportancia que presenta el porcentaje de tutores dedicados a la categoría de «oficios mecánicos y viles» en la que, siguiendo a R. Benítez, incluimos las actividades artesanales y mercantiles. La diferencia existente entre los porcentajes referidos a Alicante y Málaga, puede deberse a que la inmensa mayoría de los mercaderes instalados en Alicante a principios del siglo XVII eran extranjeros (66) y a que, por tanto, no intervinieron en los hechos de Laguar quedando ausentes del reparto del botín. Es muy probable que estos comerciantes, de haber podido intervenir en la represión de las montañas sublevadas, hubieran presentado niños a su cargo dada la probada tendencia de este grupo a la compra de esclavos. Sabemos, por ejemplo, que el $22,2 \%$ de los esclavos bautizados en la iglesia de Santa María de Alicante, entre 1589 y 1645, pertenecían a comerciantes extranjeros

(64) N. CABRILLANA, «Almería en el siglo XVI, moriscos encomendados». Revista de Árchivos, Bibliotecas y Museos, enero-junio de 1975, pp. 41-68. Concretamente, en la p. 47, hace referencia este autor a cómo en Almerf́a se dieron niños moriscos en encomienda a determinadas personas perjudicadas por la expulsión de los cristianos nuevos del reino de Granada.

(65) J. REGLA, Op. cit., p. 224.

(66) H. KAMEN, La España de Carlos III. Barcelona, 1981, pp. 186-190. 
-italianos en su totalidad-; mientras que en la parroquia de San Nicolás este porcentaje, para las mismas fechas, se elevó a un 10,0\%, siendo también los poseedores comerciantes italianos en su totalidad. El comercio de Alicante estaba todavía lejos de contar con el predominio francés de últimos del siglo XVII y de casi todo el siglo XVIII.

Quedan todavía dos aspectos importantes por dilucidar en la cuestión de los niños moriscos establecidos en Alicante. Una es la de la condición social que se les otorgaba; otra la del nivel de integración que iban a lograr dentro de la sociedad cristiana vieja. Sobre el primero de estos puntos hemos anticipado ideas que pueden hacer suponer que los niños quedaron como esclavos. No poseemos, sin embargo, ninguna prueba tajante sobre ello. Es más, la última documentación oficial que hace referencia al estado en que habían de permanecer estos menores es totalmente contraria a la idea de esclavitud. Se trata del decreto de 29-8-1611 ya mencionado en el que el monarca insiste en su política tendente a evitar esta situación para los niños. Los términos en que está redactado el documento nos permite suponer que la idea que debió prevalecer fue la de dejar a los niños en encomienda tal y como había sucedido en el siglo XVI con los niños de Almería al acabar la guerra de Granada (67). No existe en Alicante ninguna carta de encomienda redactada para legalizar la situación de los niños moriscos. Se da, sin embargo, en los protocolos notariales de Alicante y Elche un tipo de contrato similar al señalado por N. Cabrillana (68) aunque se deba a intenciones distintas: el afermament. Contrato éste por el cual los menores eran dejados por sus padres o parientes en manos de una persona a la que debían servir por un tiempo determinado a cambio del sustento y una retribución económica al finalizar la edad de encomienda. Es de suponer que los niños moriscos quedarían en una situación similar mediara o no la escritura notarial correspondiente por tratarse de una costumbre arraigada. Hay que resaltar, no obstante, que el afermament, independientemente de su valor jurídico, sometía a los niños a una situación semiservil muy acusada, en la que los padres o familiares perdían durante la vigencia del contrato la potestad sobre sus hijos. En el caso de los niños moriscos, desaparecidos los padres o responsables cosanguíneos más próximos, nadie podía pedir cuentas al encomendero al rescindirse el tiempo de tutela. Es por ello que los niños quedarían totalmente a merced de sus cuidadores incluso cuando llegase el momento de su emancipación, y no es extraño, por tanto, que se les considerase dentro de la escala social más baja. Buena prueba de ello es alguna que otra referencia contemporánea a los acontecimientos que describimos. El caso, por ejemplo, del párroco de Novelda que apuntaba lo siguiente en el libro de defunciones de su iglesia:

(67) N. CABRILLANA, Op. cit.

(68) Ibídem, p. 47. 
«En 28 de diciembre de 1611 fue sepultado un morisquillo de edad de 5 años que era esclavillo de Celsa» (69).

Sobre la práctica, pues, estaba claro cual era la condición de los niños. Pero el hecho tal vez más destacado sobre este particular nos viene dado por los libros de bautismo de las parroquias alicantinas de Santa María y San Nicolás. En ellos se reseña, como era costumbre, la impartición de este sacramento a los esclavos que adquirían las gentes de la ciudad. Aunque es preciso contar con que muchos de ellos no pasarían obligadamente por las dos parroquias - podian estar ya bautizados en los lugares de compralos datos aquí recogidos son un indicativo interesante como muestra el Gráfico n. ${ }^{\circ} 1$.

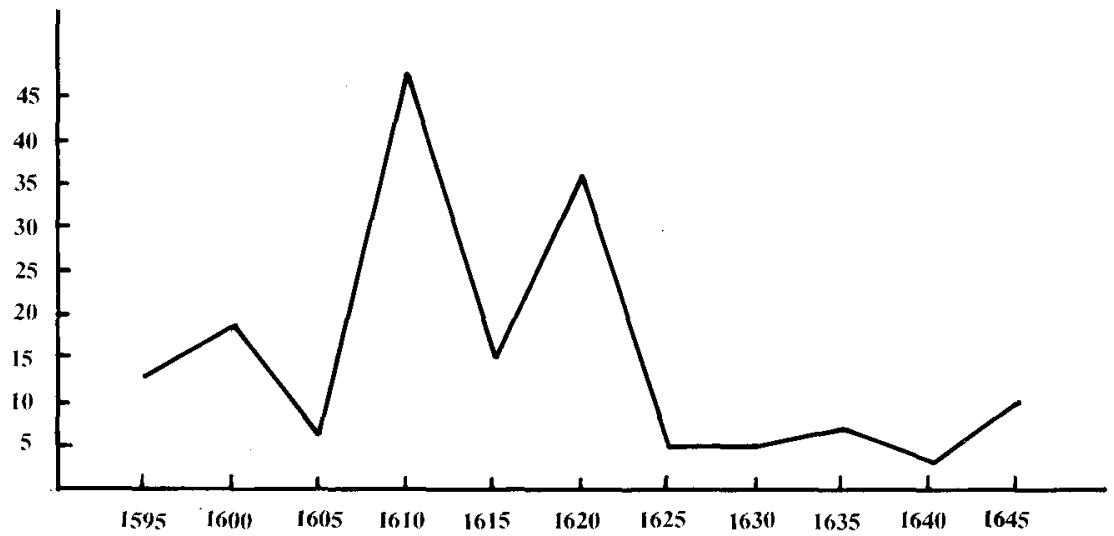

¿RAFICO No 1: Esclavos bautizados en las Parroquias de Sta. María y San Nicolás de Alicante entre 1590-1645.

(69) V. SALA CAÑELLAS, Op. cit., p. 170. 
El número de esclavos bautizados no moriscos - adultos y menores, «moros de Africa, Orán, negros», etc. como se les suele denominar para distinguirlos de los cristianos nuevos- disminuyó notablemente durante los años en que Alicante se vio sorprendida por la presencia de casi dos centenares de niños moriscos (70). En una ciudad de 6.700 habitantes para 1619 (71) en la que sólo un grupo muy reducido de personas tendrían el poder adquisitivo suficiente para comprar esclavos, esta sugerente oferta debió de repercutir en la demanda que bajaría de manera clara; máxime si esta minoría acostumbrada a ejercerla se vio en la posibilidad de satisfacer las necesidades de este tipo de servicios sin hacer ningún desembolso. Y ello parece que fue cierto, ya que resulta muy normal encontrar a las mismas personas que compran esclavos durante los veinte años anteriores a $1610 \mathrm{y}$ después, entre 1620-1640, registrando a los niños moriscos entre 1610 y 1614 , como sustitutivo ideal del esclavo. Concretamente hemos podido localizar a veinte de estas personas, casi todas ellas pertenecientes a las familias de alta alcurnia alicantina: los Martínez de Vera, los Escorcia, los Pobil, los Pascual, los Bendicho, etc. Su comprobación nombre por nombre nos ha permitido, además, ver cómo son muy abundantes también las gentes que aparecen registrando niños moriscos en los manifiestos que se encuentran vinculadas por parentesco a estas familias, pero que, por el contrario, jamás aparecieron bautizando esclavos. El botín de niños sirvió por lo tanto para que ramas laterales de las grandes familias de la oligarquía alicantina pudiesen elevar en apariencia su categoría adquiriendo servidores de modo gratuito, lo que sería una especie de revancha ante la colonia italiana de comerciảntes económicamente más poderosa, pero de inferior rango social.

Queda por aclarar el aumento que se vuelve a experimentar en los bautizos de esclavos tras 1615, para entrar, más tarde, en una línea de normalidad similar a la existente a primeros de siglo. Podría decirse que la presencia de los niños moriscos abarató el mercado de esclavos y que debido a esta razón su compra se volvió a intensificar. Pero consideremos excesivamente temerario el establecer una conclusión de este tipo basada en el único caso de Alicante y sin tener unas apoyaturas más sólidas sobre el negocio de la esclavitud en el siglo XVII. Es posible que esta hipótesis tuviese más validez haciendo referencia a los 2.450 niños (72) que quedaron en todo el Reino y a un número, todavía sin determinar, de adultos que, en efecto, pudieron hacer daño, aunque fuese momentáneamente, a los centros de tráfico humano más próximos al litoral valenciano. Dejamos pues la res-

(70) 195 para ser exactos: los 94 del primer registro, los 64 nuevos aparecidos en el segundo, los 7 nuevos del tercero y los 28 reseñados en los registros parroquiales que escaparon al control civil.

(71) P. ORTS Y BOSCH, Alicante, notas históricas (1373-1800), Valencia, 1971, pp. 42-43.

(72) H. LAPEYRE, Op. cit. p. 66. 
puesta en el aire en espera que este aspecto pueda ser estudiado con mayor amplitud, mejores fuentes y más detenimiento.

Nos resta, ahora, el tratar de averiguar hasta qué punto los niños fueron integrados en la sociedad que había expulsado a sus padres. La penuria documental de los archivos locales para el siglo XVII nos lleva de nuevo a los libros parroquiales. En ellos, en los de bautismo y matrimonio, hemos tratado de seguir la pista de estos menores con la intención de descubrir si existió algún tipo de discriminación sobre sus personas. La ausencia casi total de noticias sobre estos menores a partir de 1614 induce a pensar que, con el paso de los años, los niños se fueron incorporando paulatinamente a la vida local borrándose el recuerdo de su procedencia. El caso de la siguiente acta matrimonial es elocuente al respecto:

«Joan Baptista ab Angela. En 22 de juliol de 1635 fetes tres canoniques monicions conforme decret del S.C.T. y no constant impediment algu disposi y doni les benedictons nupcials a Joan Batista criat de la viuda de Llois Canto de una part ab Angela criada del quondam Miguel Aguirri de altra. Têstimonis al desposori mossen Hieroni Bernat y Antoni Comes y altres. Melchior Bonet curat» (73).

Se trata de una pareja de niños moriscos. Concretamente de Juan, presentado en el registro de julio de 1610 por la viuda de quien lo manifestó a la edad de siete años, y de Angela, también presentada en el mismo documento cuando tenía seis años por Miguel Aguirri ahora fallecido (74). Como puede observarse a los veinticinco años de haberse afincado en Alicante contraen ambos matrimonio sin que se haga alusión alguna a su antigua condición socio-religiosa. Este ejemplo concreto, perdido entre cientos de matrimonios entre cristianos viejos que se produjeron durante estos años, sin ninguna mención especial diferenciadora, hace suponer que muchos de los antiguos niños moriscos se encuentran en estas actas perdidos ya los vestigios de su antigua condición. Un dato que avala esta hipótesis es la excepción presentada por tres únicos casos en los que sí se manifiesta el origen confesional de los muchachos. Se trata, como decimos, tan sólo de tres casos en un espacio de más de treinta y cinco años, y han sido hallados en aquellos grupos donde la Iglesia, mediante una serie de señales, evidenciaba, para que quedase constancia, la condición anormal o marginal de los bautizados; es decir, los hijos de padres desconocidos, de esclavos, etc., cuyos nombres suelen ir precedidos por un círculo o envueltos por él. En uno de estos tres bautizos, celebrado en 1629 , leemos que se administra el sacramento a:

«...Jaume Gabriel Josepho, fill de Jaume, criat per Jaume Pasqual de Pobil dels de la expulsió y de Gerónima Sáńchez criada per Miser Bernat» (75).

(73) A.P.S.M. Libro n. 2 de matrimonio, años 1606-1687, fol. 49.

(74) A.M.A. Llibre de provisions reals... Registro de 16 de julio de 1610 , fols. $76-77$.

(75) A.P.S.N. Libro de Bautismo, 1626-1639, fol. 57. 
Los otros ejemplos restantes corresponden a 1634 y 1636 son idénticos al que acabamos de describir, haciendo, por tanto, referencia a que los padres son moriscos de los que quedaron cuando la expulsión.

Hemos de concluir, pues, pensando que una sociedad como la española del siglo XVII en la que la limpieza de sangre siguió siendo un requisito básico para cualquier tipo de promoción social, y en la que el testimorio de la Iglesia resultaba uno de los datos más decisivos en las testificaciones, el hecho de que sólo aparezcan estos tres casos constatados habla muy a favor del espíritu tolerante con que los alicantinos acogieron a los hijos de los moriscos. De no ser así hemos de pensar en algo más raro: en la desaparición casi total de los menores de Alicante a partir de 1614 a causa de las razones más diversas.

No quisiéramos acabar este artículo sin dejar constancia de una serie de detalles que aparecen todavía en los tres manifiestos estudiados. Nos referimos a la manera en que los comisarios reales y sus escribanos vieron a los niños moriscos y al modo como los describieron. Algo, que estudiado tal vez para esos dos millares y medio de muchachos que se registraron bajo las órdenes de D. García Bravo de Acuña podría ser una pequeña pista para terciar en el espinoso tema de las posibles, o no, diferencias raciales entre cristianos viejos y moriscos, y para tratar de apoyar las ideas que existen sobre la incidencia de ciertas enfermedades contagiosas entre la población infantil de la época preindustrial.

Los comisarios en cuestión se tomaron mucho interés en anotar los rasgos físicos más sobresalientes de los niños, aquellos que, a su juicio, eran los más diferenciados y podían posibilitar su identificación en un futuro. Apuntaron, así, datos sobre el color de su piel, sobre los defectos más acusados de su fisonomía, sobre las heridas o defectos que presentaban, etc. De los 123 niños que aparecen en el manifiesto aludido, consideraron digno de reseñar, por ejemplo, el hecho de que el 14,7\% fueran «morenos de rostro», en tanto y cuanto sólo el 3,3\% destacaban por ser «blancos» dentro de una normalidad sobre la pigmentación que ignoramos. Bajo el calificativo de «chatos» o «camuzos» aparecieron el 16,3\%, uri porcentaje no despreciable como rasgo característico; idéntica proporción presentaron los niños que tenían huellas visibles de haber padecido la viruela.

En espera de poder ofrecer pronto los datos tabulados para el resto de los niños que quedaron en todo el Reino, podemos adelantar las apreciaciones que, sobre este particular, aparecen en el documento de Onteniente transcrito por V. Castañeda (76). En él de los 42 ninos manifestados en 1611 , el $42,8 \%$ eran también «morenos de rostro», solo el $6,1 \%$ «blancos»; el $2,5 \%$ eran «chatos de narices» y el $9,5 \%$ «ojossos de viruela». También

(76) Ver nota $n .^{\circ}(2)$. 
para Elche (77) tenemos noticias de los rasgos más destacados de los niños que allí quedaron. En octubre de 1611 se contabilizaron tan solo 8, pero dándose asimismo la circunstancia de que 2 de ellos presentaban marcas de viruela mientras que otros tantos sobresalían por sus «anchas narices».

IV. - A modo de conclusión podemos decir que el número de niños mỏoriscos en Alicante, entre los aparecidos en los registros civiles y religiosos (78) alcanzó la cifra de 195, lo que vino a significar en relación con la población ciudadana un incremento de la misma del $2,9 \%$, porcentaje que se acerca mucho, por otro lado, al de los niños bautizados anualmente en las dos parroquias de la ciudad durante las cuatro primeras décadas del siglo XVII. Dada la condición de trabajadores para el servicio doméstico a que quedaron sometidos, su integración de la sociedad alicantina no debió encontrar otros obstáculos más que los derivados de este rango socio económico, unido a las lógicas dificultades de promoción (las noticias que poseemos sobre ellos, años después de 1614 los siguen vinculando a las mismas tareas, siendo muy probabie que incluso la primera generación de su descendencia siguiera dedicándose a la misma actividad). Por la misma razón resulta difícil imaginar que este reducido número de muchachos, desarraigados de sus lugares de origen, de base principalmente rural, pudieran dejar alguna huella de tipo cultural o etnográfico en el seno de una sociedad urbana más dinámica y predominantemente comercial. Otra cosa distinta pudiera haber ocurrido en lugares de escasa población cristiano-vieja de las montañas donde también quedaron niños en mayor porcentaje relativo que en Alicante y en circunstancias más propicias para su comunicación y para lograr hacer más perdurable usos y costumbres de sus mayores. Si en un futuro próximo podremos estar en condiciones de ofrecer para el Reino de Valencia los datos numéricos y de interpretación que hemos elaborado en el presente trabajo para Alicante, otra cosa bien distinta ocurre para rastrear los vestigios culturales, sobre ios cuales, sólo un minucioso estudio de los procesos inquisitoriales por un lado, y el auxilio de la etnografía por otro, podrían posibilitar una conclusión más definitiva del tema.

(77) A.M.E. Llibre de Sitiades, 1611, fol. correspondiente al 7 de octubre de 1611. Arm. 1.

(78) Ver nota $n .^{\circ}(70)$. 